\title{
Improving Adiabatic Film Cooling Effectiveness Using a Chevron Shape Ramp
}

\author{
Grine Mustapha ${ }^{1, *}$, Ben Ali Kouchih Fatima², Boualem Khadidja², Azzi Abbès ${ }^{2}$ \\ ${ }^{1}$ ELM Department, Institute of Maintenance and Industrial Safety, Oran 2 University, Oran, Algeria. \\ ${ }^{2}$ Laboratoire Aero Hydrodynamique Navale, (LAHN) USTO-MB, Oran, Algeria.
}

\begin{abstract}
How to cite this paper: Grine Mustapha, Ben Ali Kouchih Fatima, Boualem Khadidja, Azzi Abbès. (2021) Improving Adiabatic Film Cooling Effectiveness Using a Chevron Shape Ramp. Journal of Electrical Power \& Energy Systems, 5(1), 24-32.

DOI: 10.26855/jepes.2021.04.001
\end{abstract}

Received: March 1, 2021

Accepted: March 28, 2021

Published: April 29, 2021

*Corresponding author: Grine Mustapha, ELM Department, Institute of Maintenance and Industrial Safety, Oran 2 University, Oran, Algeria.

Email: grine890@gmail.com

\begin{abstract}
In this study, two geometrical configurations are considered for purpose comparison, which are the base line case, and the case with an upstream chevron with rounded edge. The ensemble-averaged Navier Stokes equations closed by the k- $\varepsilon$ RNG turbulence model and standard wall function are used in frame of the finite volume method, computational Fluid Dynamic (CFD) code represented by the commercial programmers ANSYS CFX 14.0. The work consists of a numerical computation study of a film cooling on a flat plate. The goal is to verify the effectiveness of the present code by applying the same boundary conditions on the same geometry. Furthermore, another dimension of the physical domain was displayed by adding the concept of upstream chevron fence. Three blowing ratios are considered $(0.50,1.00$, and 1.50) and length-to-diameter ratios 1.75 . Results are shown in form of centerline adiabatic film cooling effectiveness. The most important element in this study is the film cooling effectiveness. This variable will be the subject of most of the results in this work.
\end{abstract}

\section{Keywords}

Film Cooling, Chevron, Upstream Chevron, Spanwise, $\mathrm{CRV}_{\mathrm{S}}$, Anti $\mathrm{CRV}_{\mathrm{S}}$

\section{Introduction}

In the gas turbine industry, the efficiency and the power of the machines are proportional to the highest temperature of the cycle. This temperature corresponds to that of the combustion gases which directly attack the blades of the first gas turbine stage, hence the obligation to adopt sophisticated and well-studied cooling processes. Film cooling is the excellent method widely used in modern machines.

The phenomenon that comes down academically to a jet interacting with a transverse flow with heat transfer is difficult to predict numerically. Several studies have shown that turbulent viscosity and averaged velocity turbulence models are not able to effectively reproduce the transfer phenomenon.

The published scientific literature, experimental and numerical investigations have been conducted in order to understand the complex mechanisms of film cooling process. These studies are conducted either for flat plate [1, 2] and/or leading edge turbine blades $[3,5]$ where several geometrical parameters are investigated.

Thus, many investigations are directed in such a way to control these vortices in order to enhance the film cooling process. To do that, one can modify the hole geometry itself like using compound [6] and/or shaped holes [7], adding tabs placed at the film-cooling-hole exit [8], using a converging slot-hole (console) [9-11] or creating a 
trench about a row of film-cooling Holes[12,13]. All these techniques concentrate on the hole geometry to modify the boundary-layer/cooling jet interactions.

In many of the previous studies, Kelso and Lim [14] and Haven, et al. [15] showed the importance vortices in the evolution of film-cooling jets. One pair, referred to as the counter rotating vortices (CRVs), was found to lift the jet off the surface that it is intended to protect and to entrain hot gases under it.

The other pair, referred to an anti-CRV pair, was shown to have an opposite sense of rotation to that of the CRVs, and so can counteract the undesirable tendencies of the CRVs [16].

The present study aims to propose a configuration that was modified by adding the concept of ramp (chevron) in upstream of the injection hole to study its effects on film cooling effectiveness.

\section{Flow Geometry, Grids and Boundary Conditions}

Two configurations are considered in this study. The first is a simple cylindrical injection hole based on the experimental work of Sinha et al. [22]. For the second, a new modification based on the concept of a Chevron in upstream of the injection holes.

Figure 1 shows the geometry of chevron -shaped ramp while Figure 2 presents the domain of calculation appropriate to the simulation.

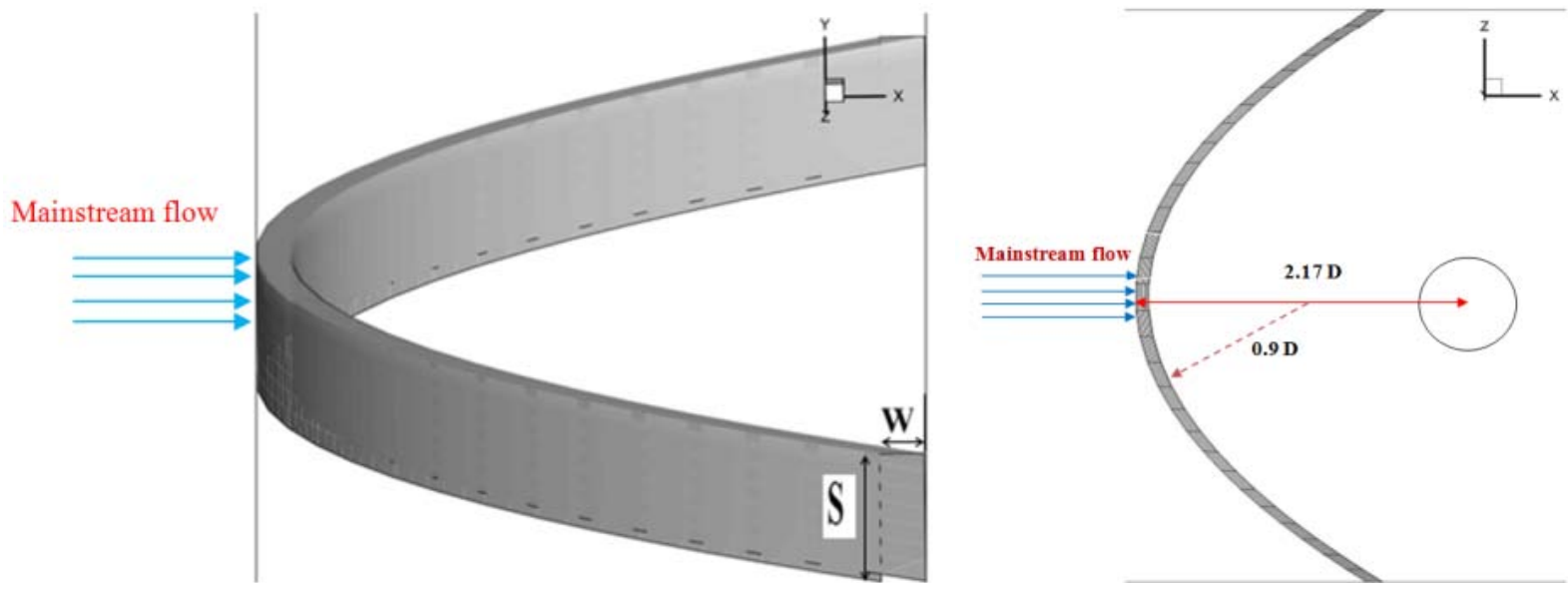

Figure 1. Schematic of the geometric configuration of the Chevron shaped ramp.

$50 \mathrm{D}$

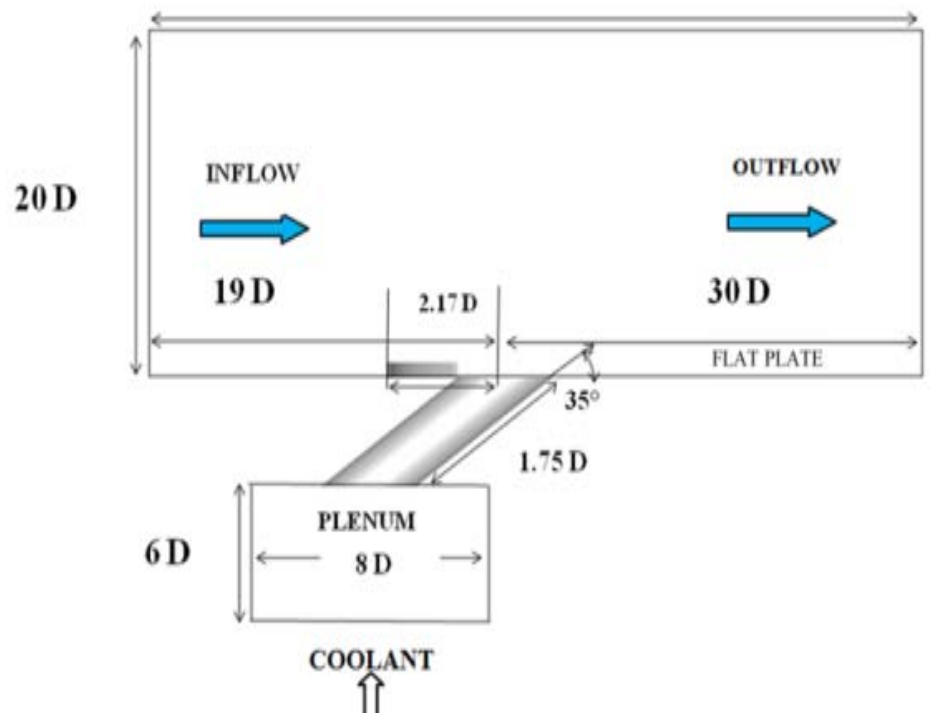

Figure 2. Computation domain and the boundary conditions. 


\section{Computational Domain and Boundary Conditions}

\subsection{Computational Domain}

A single row of cylindrical holes inclined of $35^{\circ}$ in the flow direction is considered for both cases. The lateral spacing of the holes is set to $3 \mathrm{D}$, where $\mathrm{D}$ is the diameter of the hole $(\mathrm{D}=12.7 \mathrm{~mm})$. One hole length/diameter ratio of 1.75 is considered in this study. The range of calculation extends from the input plane up to 50D in flow streamwise direction and from the bottom of the flat plate to 20D in the vertical direction.

In the spanwise direction, the domain extends between two injection holes. The conditions of symmetry are imposed on the lateral planes. In order to improve the application of the velocity profile of the flux injected at the entrance of the hole injection, a plenum is introduced into the computational domain while the boundary layer has been fully developed.

\subsection{Boundary Conditions}

The boundary conditions are defined in the CFX Pre module of CFX14 calculation code. The flow velocity of the mainstream was set at $U=20 \mathrm{~m} / \mathrm{s}$, according to the experience of Sinha et al. [22]. A turbulence intensity of the free flow $\mathrm{Tu}=5 \%$ is taken into account and the relative pressure is equal to 0 bar at the outlet of the two flows (mainstream and secondary). And a dimensionless eddy viscosity of $\mu_{t} / \mu_{\infty}=50$. On the wall surface of the flat plate, the employed boundary conditions were the no-slip conditions for the velocity and the adiabatic state for the temperature. Similar conditions were applied to the pipe and plenum internal walls. Because the upper surface of the domain was set relatively far from the flat plate the density ratios between the injection flow and the main flows are kept as in the experimental configuration $\rho_{j e t} / \rho_{\infty}=1.2$. The working flow temperature is set to Air at $300{ }^{\circ} \mathrm{K}$, and $250{ }^{\circ} \mathrm{K}$ for the secondary jet, three injection ratios of $0.5,1.0$ and 1.5 are considered.

\subsection{Turbulence Modelling}

To carry out this work, several simulations were conducted using ANSYS CFX 14.0 software. In the solver package, the solution of the Reynolds Averaged Navier-Stokes Equations (RANS) is obtained by using finite volume method for discretization of the continuity, momentum, and energy equations. The second-order upwind solution scheme is used to solve the momentum, energy, and turbulence model equations. The SIMPLEC algorithm is employed to solve the pressure-velocity coupling. The Reynolds Averaged Navier-Stokes (RANS) equations can be written as follows:

$$
\begin{gathered}
\frac{\partial\left(\rho u_{i}\right)}{\partial x_{i}}=0 \\
\frac{\partial\left(\rho u_{j} u_{i}\right)}{\partial x_{j}}=\frac{\partial}{\partial x_{j}}\left[\mu\left(\frac{\partial u_{i}}{\partial x_{j}}+\frac{\partial u_{j}}{\partial x_{i}}\right)-\left(\frac{2}{3} \mu \frac{\partial u_{i}}{\partial x_{i}}\right)\right]-\frac{\partial p}{\partial x_{i}}+\frac{\partial}{\partial x_{j}}\left(-\rho \overline{u_{i}^{\prime} u_{j}^{\prime}}\right)
\end{gathered}
$$

Modelling of the Reynolds stresses $\left(-\rho \overrightarrow{u_{i}^{\prime} u_{j}}\right)$ in equation (2) is done using Boussinesq hypothesis which relates the Reynolds stresses to the mean velocity gradients via the equation (3) below:

$$
-\rho \overline{u_{i}^{\prime} u_{j}^{\prime}}=\mu_{t}\left(\frac{\partial u_{i}}{\partial x_{j}}+\frac{\partial u_{j}}{\partial x_{i}}\right)-\frac{2}{3}\left(\rho k+\mu_{t} \frac{\partial u_{i}}{\partial x_{i}}\right) \delta_{i j}
$$

Turbulent quantities in the Navier-Stokes equations are treated using the turbulent viscosity $\left(\mu_{\mathrm{t}}\right)$ is given by

$$
\mu_{t}=\rho C_{\mu} \frac{k^{2}}{\varepsilon} C_{\mu}=0.085
$$

According to literature survey, the $R N G k-\varepsilon$ model is more consistent with the experimental data for the prediction of film cooling effectiveness than those obtained by other models. This model has been adopted in our work. A detailed explanation of the model formulation and test case validations can be found in specific literature of Yaghot [25]; whereas, only the mathematical equations of the model are presented here. 


$$
\begin{gathered}
\frac{\partial}{\partial t}(\rho \varepsilon)+\frac{\partial}{\partial x_{j}}\left(\rho \varepsilon u_{i}\right)=\frac{\partial}{\partial x_{j}}\left[\left(\mu+\frac{\mu_{t}}{\sigma_{\epsilon}}\right) \frac{\partial_{\varepsilon}}{\partial x_{j}}\right]+P_{k}-\rho \varepsilon \\
\frac{\partial}{\partial t}(\rho \varepsilon)+\frac{\partial}{\partial x_{j}}\left(\rho \varepsilon u_{i}\right)=\frac{\partial}{\partial x_{j}}\left[\left(\mu+\frac{\mu_{t}}{\sigma_{\varepsilon}}\right) \frac{\partial_{\varepsilon}}{\partial x_{j}}\right]+C_{1 \varepsilon} \frac{\varepsilon}{k}-P_{k}-C_{2 \varepsilon}^{*} \rho \frac{\varepsilon^{2}}{k} \\
\text { Or } \quad C_{2 \varepsilon}^{*}=C_{2 \varepsilon}+C_{2 \varepsilon}+\frac{C_{\mu}\left(1-\frac{\eta}{\eta_{\circ}}\right)}{1+\beta \eta_{\circ}} \\
\text { and } \eta=S k / \varepsilon \text { and } \mathrm{S}=\left(2 \mathrm{~S}_{\mathrm{ij}} \mathrm{S}_{\mathrm{ij}}\right)^{1 / 2}
\end{gathered}
$$

The constant of RNGk $-\varepsilon$ model are mentioned below:

Table 1. Constants of turbulence model

\begin{tabular}{|c|c|c|c|c|c|c|}
\hline $\mathrm{C}_{\mu}$ & $\sigma_{k}$ & $\sigma_{\varepsilon}$ & $\mathrm{C}_{\varepsilon 1}$ & $\mathrm{C}_{\varepsilon 2}$ & $\eta_{\circ}$ & $\beta$ \\
\hline 0.0845 & 0.7194 & 0.7149 & 1.42 & 1.68 & 4.38 & 0.012 \\
\hline
\end{tabular}

\section{Presentation of the Chevron Shape Ramp Case}

As the base case, keeping the same geometric parameters, we added a chevron shape ramp in the new geometry. This chevron was added upstream of the injection hole at a distance $\mathrm{L}=2.17 \mathrm{D}$ from the center of the latter, with a height $\mathrm{S}=\mathrm{D} / 4$ and $\mathrm{W}=0.0875$ as shown in Figure 1 . The geometric configuration of the chevron shape ramp model was taken from the numerical study of Antar M. M. Abdala, Fifi N. M. Elwekeel [23].

\subsection{Computational Grid}

In this study, the meshing is performed for an injection ratio $M=0.5$ for central adiabatic film cooling. Three meshing about 1,000,000, 1,500,000 and 2,000,000 hexahedral elements were tested. The mesh of 1,000,000 hexahedral cells was adopted in our work forits compatibility with the experimental study of Sinha et al, as shown in Figure 3. The meshing refining is more pronounced near the walls and in the vicinity of the injection hole. The calculation grid was created using ICEM CFD 14.0. Figure 4 shows a simple zoomed region of the computational grid of the injection hole, with the proposed model (chevron shape ramp).

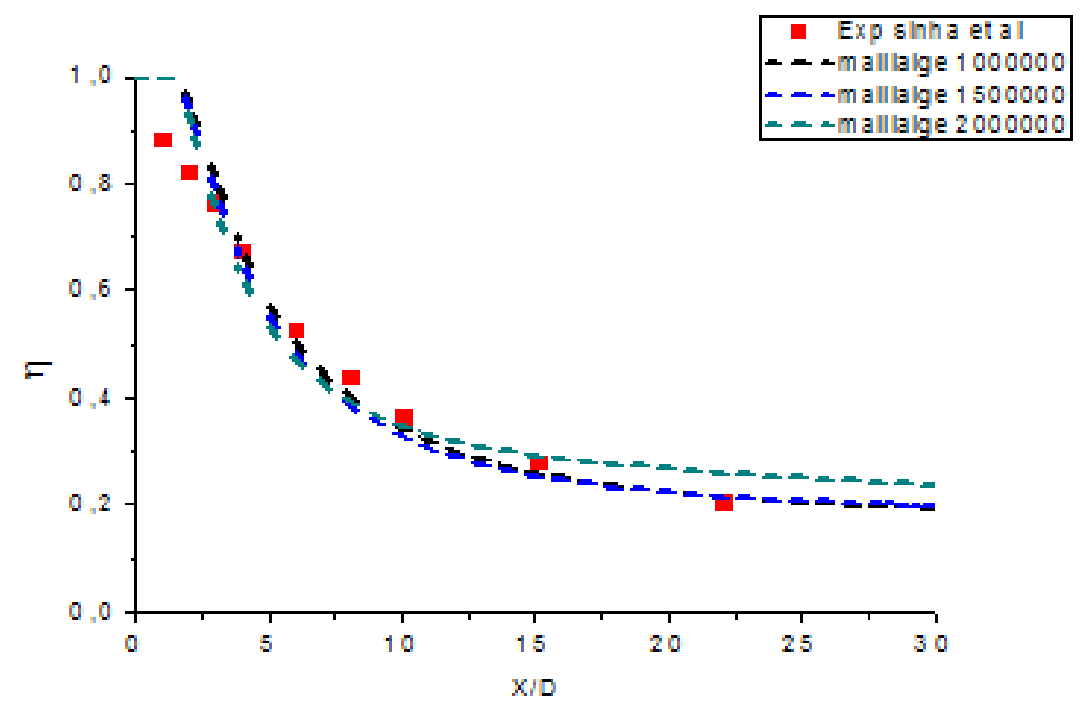

Figure 3. Sensitivity grid, Centerline adiabatic film cooling effectiveness for three different meshing. 


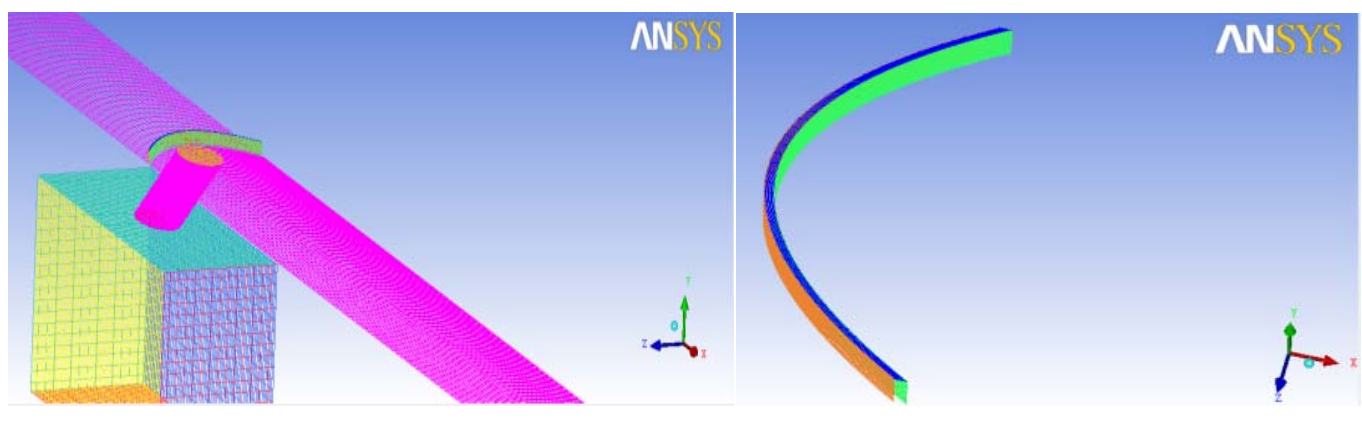

Figure 4. The calculation grid for the chevron shape ramp case.

\section{Results and Discussion}

In this section, the discussion will be based on the so-called the adiabatic film cooling effectiveness, defined by:

$$
\eta=\frac{T_{\infty}-T}{T_{\infty}-T_{c}}
$$

Where $T_{\infty}$ and $T_{c}$, stands for the main flow and the jet temperature respectively. Adiabatic film cooling effectiveness is defined in such a way to be 1 for perfect cooling and 0 for no cooling at all, Blowing ratio and hole length-to-diameter are the two parameters used in the present study. Blowing ratio $(M)$ is defined by:

$$
M=\frac{\rho_{f} U_{f}}{\rho_{\infty} U_{\infty}}
$$

Where $\rho_{f}$ and $\rho_{\infty}$ are the jet and main flow densities, while $U_{f}$ and $U_{\infty}$ are the perpendicular velocities of jet and main flow respectively. In all present computations, the density ratio is fixed at 1.2. As in Sinha's [22] experiment, $U_{\infty}$ is fixed at $20 \mathrm{~m} / \mathrm{s}$ and $U_{f}$ is computed according to targeted blowing ratio. Boundary inlet velocity at plenum entry is computed according the mass conservation law.

\subsection{Centerline Adiabatic Film Cooling Effectiveness}
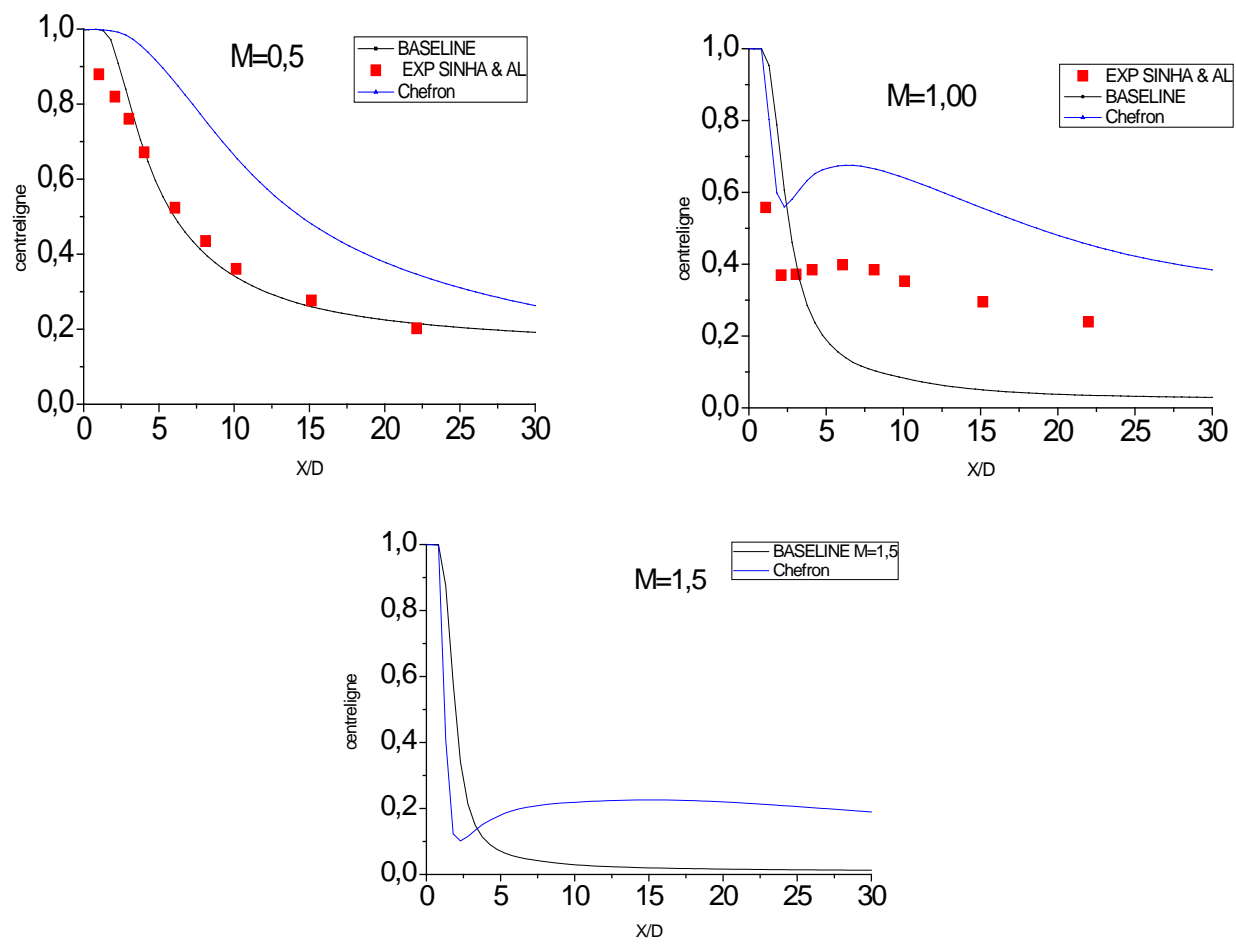

Figure 5. Centerline adiabatic film cooling effectiveness $M=0.5 ; M=1.00$ and $M=1.50$. 
Figure 5 represents the Centerline adiabatic film cooling effectiveness for the injection ratios $\mathrm{M}=0.5$ and $\mathrm{M}=$ 1.0 and $\mathrm{M}=1.50$ for an $\mathrm{L} / \mathrm{D}=1.75$. We note a good concordance of the results obtained with the experimental results of Sinha et al.

For the 0.50 blowing ratio, we observe that the jet remains attached to the wall, then the laterally averaged adiabatic film cooling effectiveness decreases monotonically in the streamwise direction. About the height blowing ratio $(\mathrm{M}=1.0,1.5)$ it is clear that the film cooling effectiveness decreases with the increase of the injection ratio $\mathrm{M}$ which increases the jet inertia and causes the detachment of this one.

We also note that the case of Chevron gives a better prediction and higher film cooling effectiveness along the surface of flat plane.

For the height blowing ratio $\mathrm{M}=1.00$ and $\mathrm{M}=1.50$, we show that the case of Chevron gives a better effectiveness compared to the case of Baseline after a distance of X/D $>2.5 \mathrm{D}$. This attributes to generating a higher pressure difference region for chevron fence witches help to spread the coolant in a lateral direction higher than the case without chevron concept.

\subsection{Adiabatic Film Cooling Effectiveness on the plate flat for Different Injection Ratios}

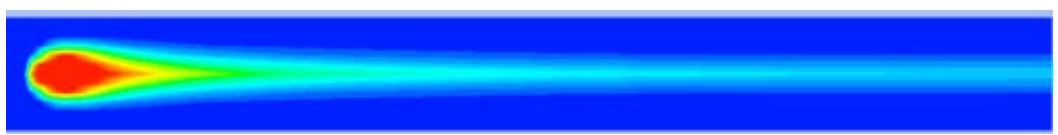

Baseline case $\mathrm{M}=0.50$

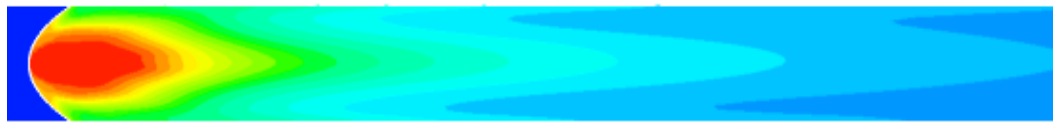

Chevron case $\mathrm{M}=0.50$

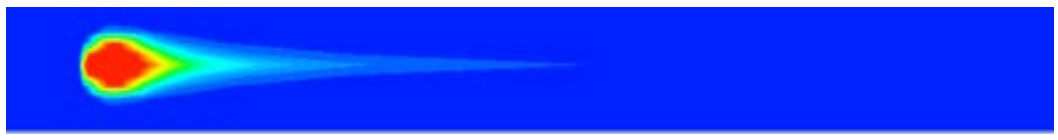

Baseline case $\mathrm{M}=1.00$

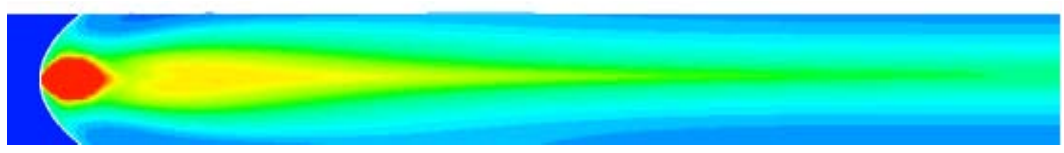

Chevron case $\mathrm{M}=1.00$

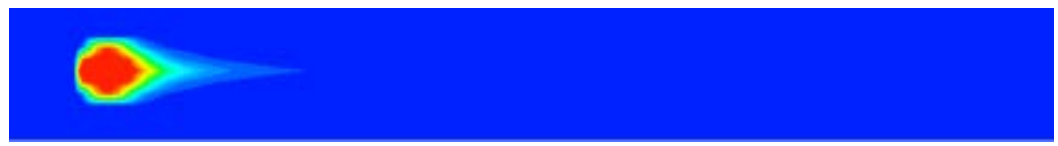

Baseline case $\mathrm{M}=1.50$

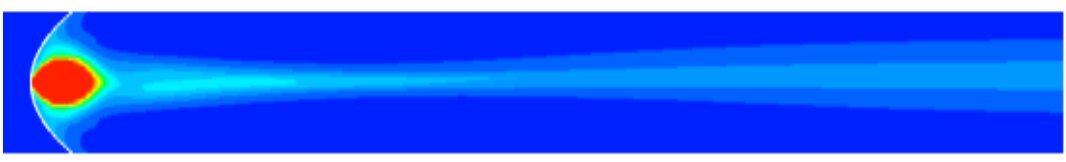

Chevron case $\mathrm{M}=1.50$

\section{$\begin{array}{lllllllll}0.1 & 0.2 & 0.3 & 0.4 & 0.5 & 0.6 & 0.7 & 0.8 & 0.9\end{array}$}

Figure 6. Adiabatic Film Cooling Effectiveness on the plate flat for Different Injection Ratios $\mathbf{M}=\mathbf{0 . 5} ; \mathbf{M}=1.00$ and $\mathbf{M}=1.50$.

Figure 6 represents adiabatic film cooling effectiveness on the flat plane for different injection ratios $\mathrm{M}=0.5$; $\mathrm{M}$ $=1.00$ and $\mathrm{M}=1.50$. We notice that for low injection ratios, the case of Baseline shows that the jet remains attached to the hole, the space between the injection holes is less well protected than in the case chevron chap ramp. The adiabatic film cooling effectiveness in the case of chevron shape ramp is always better than that of the Baseline case. 
In the case of chevron, the area covered by the cooling film is almost double that of Baseline. It is also can be seen that the film cooling coverage improves in lateral direction of the jet.

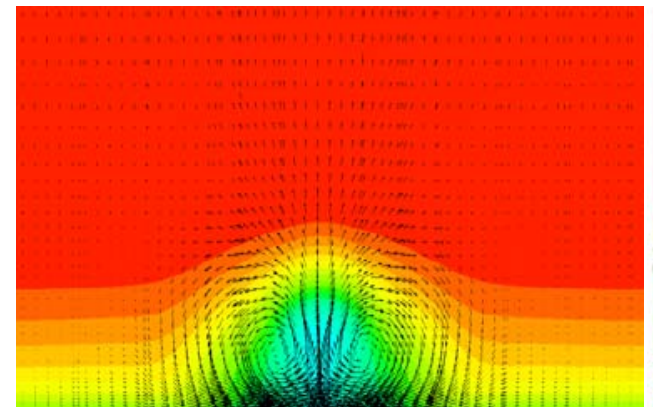

Baseline case $\mathrm{M}=0.50$

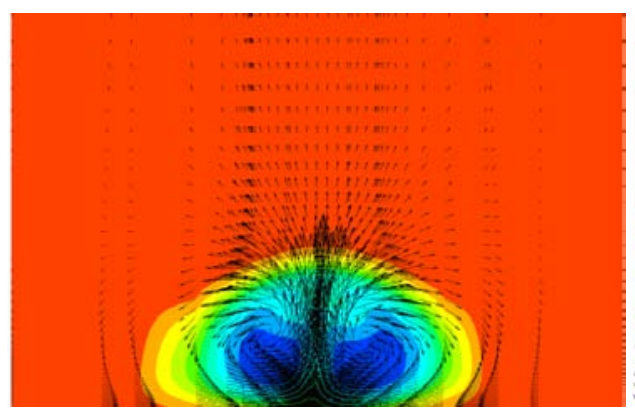

Baseline case $\mathrm{M}=1.00$

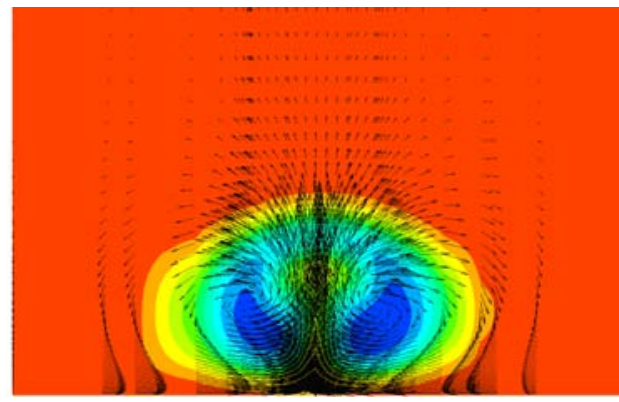

Baseline case $\mathrm{M}=1.50$

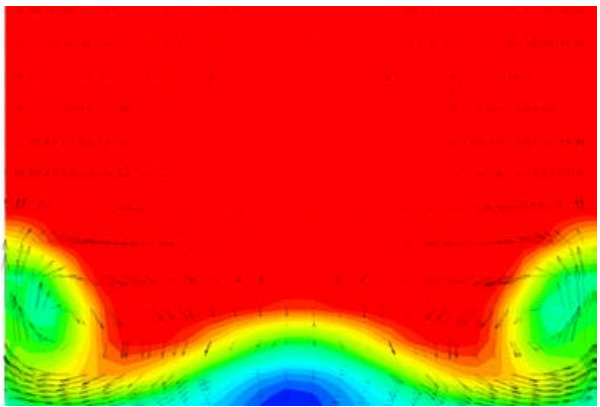

Chevron case $\mathrm{M}=0.50$

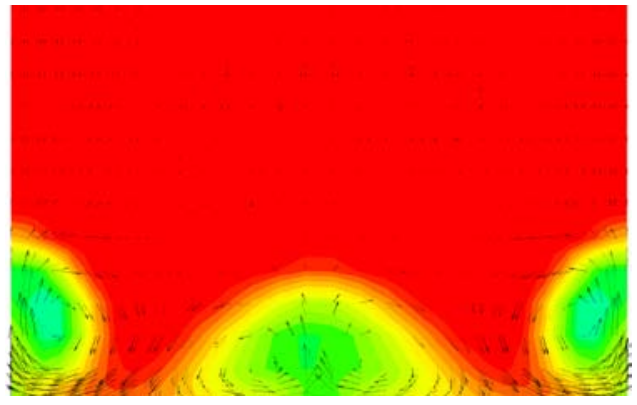

Chevron case $\mathrm{M}=1.00$

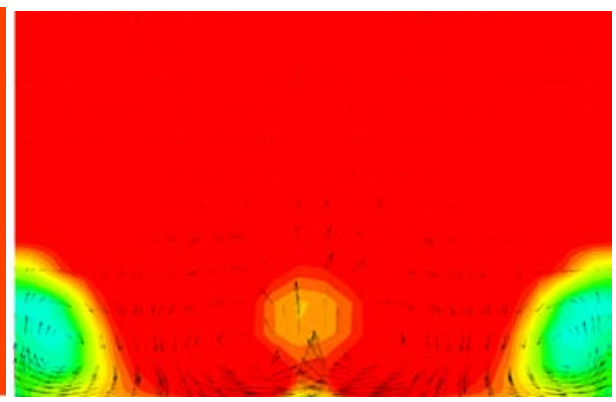

Chevroncase $\mathrm{M}=1.50$

Figure 7. Velocity vectors for the Baseline case of and the Chevron shape ramp case of the flat plate for different injection ratios at $\mathrm{X} / \mathrm{D}=3 \mathrm{M}=0.5, \mathrm{M}=1.0$ and $\mathrm{M}=1.5$.

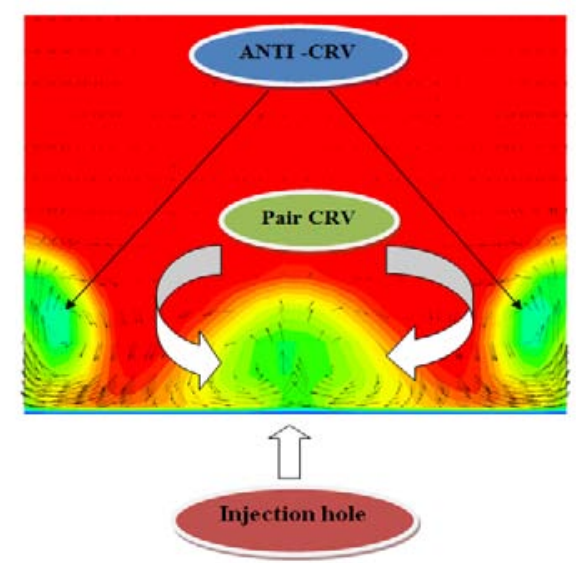

Figure 8. Schematic of velocity vector. 
In the case of Baseline, the CRV pair with a high density of velocity vectors at both sides of the plate in the lateral direction as showed by several studies [8], [9], [10]. In the case of chevron, the vectors are in opposite direction to

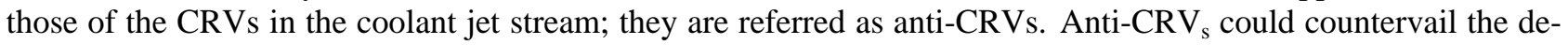
trimental effects of CRVs in the cooling jet stream. Consequently, the separation of the coolant jet stream from the surface of the plate will be postponed due to the existence of Chevron in comparison with the baseline case. The distance between the CRVs was found to be elongated in the lateral direction due to the existence of chevron.

\section{Conclusion}

In this work, the chevron concept setting in upstream of the injection hole has been numerically studied. The results are obtained by the computational simulation of film cooling through two configurations, with a comparison of injection ratio.

The first case is a Baseline configuration with a flat plate with simple cylindrical hole. The second case is a chevron configuration. The results obtained show that the performance of film cooling effectiveness is much better with chevron case than with Baseline case. From this results we note that the most favorable rate for the two configurations is $\mathrm{M}=0.50$.The presence of the chevron in upstream of the injection hole acts as an obstacle for the hot flow. This has a significant effect on the film cooling effectiveness. We have also demonstrated that the presence of Chevron creates velocity vectors playing the role of anti-CRV.

\section{Nomenclature}

D film-cooling hole diameter

$L \quad$ spanwise dimension of the plate

$l$ length of the injection hole

$M \quad$ Blowing ratio

$T$ temperature

$U$ velocity

$S$ height

W width

\section{Greek}

$\eta \quad$ adiabatic effectiveness

$\rho$ density

\section{Subscripts}
$\infty \quad$ Free-stream
C Plenum

\section{References}

[1] P. M. Ligrani, J. M. Wigle, S. Ciriello, and S. M. Jackson. (1994). Film-Cooling from Holes with Compound Angle Orientations: Part 1: Results Downstream of Two Staggered Rows of Holes with 3D Spanwise Spacing. Journal of Heat Transfer, vol. 116, pp. 341-352, 1994.

[2] P. M. Ligrani, J. M. Wigle, and S. M. Jackson. (1994). Film-Cooling from Holes with Compound Angle Orientations: Part 2: Results Downstream of a Single Row of Holes with 6D Spanwise Spacing. Journal of Heat Transfer, vol. 116, pp. 353-362, 1994.

[3] Salcudean, He. P. M. and Gartshore, I. S. (1995). Computation of Film Cooling for the Leading Edge Region of a Turbine Blade Model, ASME Paper 95-GT-20, ASME Turbo Expo 1995, Houston, Texas, June 1995.

[4] Fadéla Nemdili, Abbès Azzi, Georgios Theodoridis and Bassam Ali Jubran. (2008). Reynolds Stress Transport Modeling of Film Cooling at the Leading Edge of a Symmetrical Turbine Blade Model. Heat Transfer Engineering, 29(11): 950-960, 2008.

[5] Q. Zhang and P. M. Ligrani. (2006). Numerical Predictions of Stanton Numbers, Skin Friction Coefficients, Aerodynamic Losses, and Reynolds Analogy Behavior for a Transsonic Turbine Vane, Numerical Heat Transfer, Part A: Applications, Volume 49, Issue 3, February 2006, pp. 237-256.

[6] P. M. Ligrani and J. S. Lee. (1996). Film Cooling from Two Staggered Rows of Compound Angle Holes at High Blowing Ratios. International Journal of Rotating Machinery, vol. 2, no. 3, pp. 201-208, 1996. 
[7] Bunker, R. S. (2005). “A Review of Shaped Hole Turbine Cooling Technology.” ASME J. Heat Transfer, 127, pp. 441-453.

[8] Ekkad, S. V., Nasir, H., and Acharya, S. (2003). “Flat Surface Film Cooling from Cylindrical Holes with Discrete Tabs,” J. Thermophys. Heat Transfer, 17(3), pp. 304-312.

[9] Sargison, J. E., Guo, S. M., Oldfield, M. L., Lock, G. D., Rawlinson, A. J. (2002). A converging slot-hole film-cooling geometry-part 1: low-speed flat-plate heat transfer and loss. ASME J Turbomachinery, 124: 453-460.

[10] Sargison, J. E., Guo, S. M., Oldfield, M. L., Lock, G. D., Rawlinson, A. J. (2002). A converging slot-hole film-cooling geometry-part 2: transonic nozzle guide vane heat transfer and loss. ASME J Turbomachinery, 124: 461-471.

[11] Abbes Azzi and Bassam A. Jubran. (2007). Numerical modelling of film cooling from converging slot-hole. Heat Mass Transfer, (2007), 43: 381-388.

[12] Bunker, R. S. (2002). Film Cooling Effectiveness Due to Discrete Holes Within Transverse Surface Slots, Proceedings IGTI Turbo Expo, Amsterdam. The Netherlands, ASME Paper No. GT-2002-30178.

[13] S. Baheri and B. A. Jubran. (2012). The Effect of Turbulence Intensity on Film Cooling of Gas Turbine Blade from Trenched Shaped Holes. J. Heat\& Mass Transfer, 05/2012; 48(5).

[14] Kelso, R. M., Lim, T. T., and Perry, A. E. (1996). “An Experimental Study of Round Jets in Cross-Flow,” J. Fluid Mech., 306, pp. 111-144.

[15] Haven, B. A., Yamagata, D. K., Kurosaka, M., Yamawaki, S., and Maya, T. (1997). “Anti-Kidney Pair of Vortices in Shaped Holes and Their Influence on Film Cooling Effectiveness,” ASME Paper No. 97-GT-45.

[16] Sangkwon Na Tom I-P. Shih. (2007). Increasing Adiabatic Film-Cooling Effectiveness by Using an Upstream Ramp, Journal of Heat Transfer, vol. 129, pp. 464-471, 2007.

[17] ANSYS CFX Introduction, Release 14.0, November 2011.

[18] X. Z. Zhang and I. Hassan. (2006). Film Cooling Effectiveness of an Advanced-Louver Cooling Scheme for Gas Turbines, J. Thermophys. Heat Transfer, vol. 20, pp. 754-763, 2006.

[19] Victor Yakhot1 and Leslie M. Smith. (1992). The Renormalization Group, the e-Expansion and Derivation of Turbulence Models. Journal of Scientific Computing, Vol. 7, No. 1, 1992, Vi.

[20] A. Zeghib and Ktalbi. (2008). Comparaison des différents modèles de turbulence d'un écoulement aérodynamique dans un cyclone, Revue des Energies Renouvelables CISM’08 Oum El Bouaghi, (2008), pp. 311-324.

[21] Kuldeep Singh, B. Premachandran, and M. R. Ravi. (2017). Experimental and numerical studies on film cooling with reverse backward coolant injection. J Thermal Science, vol. 111, pp. 390-408, 2017.

[22] Sinha, D. Bogard, and N. Crawford. (1991). Film Cooling Effectiveness Downstream of a Single Row of Holes with Variable Density Ratio. J. Turbomach., vol. 113, pp. 442-449, 1991.

[23] Antar M. M. Abdala, Fifi N. M. Elwekeel. (2017). Pressure distribution effects due to chevron fences on film cooling effectiveness and flow structures. Applied Thermal Engineering, 110(2017), 616-629. 